\section{ABCS}

How to cite this article: Saes et al.

Rheumatic diseases and associated factors in older adults: a Brazilian population-based study. ABCS Health Sci. 2021;46:e021218.

https://doi.org/10.7322/abcshs.2020049.1498

Received: Jun 04, 2020

Revised: Oct 10, 2020

Approved: Oct 23, 2020

Corresponding author: Mirelle Oliveira Saes - Universidade Federal do Rio Grande - Rua Visconde de Paranaguá, 102 - Bairro Centro - CEP: 960203- 900 - Rio Grande (RS),

Brasil - E-mail: mirelleosaes@gmail.com

Declaration of interests: nothing to declare

This is an open access article distributed under the terms of the Creative Commons Attribution License

(C) 2021 The authors

\title{
Rheumatic diseases and
} associated factors in older adults: a Brazilian populationbased study

\author{
Mirelle Oliveira Saes ${ }^{1}$, Karla Pereira Machado ${ }^{2,3}$, Luiz Augusto Facchini ${ }^{3}$, Elaine Thumé ${ }^{3}$ \\ ${ }_{1}^{1}$ Programa de Ciências da Saúde, Universidade Federal do Rio Grande (UFRG) - Rio \\ Grande (RS), Brazil \\ 2Programa de Pós-Graduação em Saúde Pública, UFRG - Rio Grande (RS), Brazil \\ ${ }^{3}$ Programa de Pós-Graduação em Enfermagem, Universidade Federal de Pelotas (UFPel) - \\ Pelotas (RS), Brazil
}

\begin{abstract}
Introduction: Rheumatic diseases have high occurrence in older adults, which may lead to a reduction in independence and quality of life. Objective: To calculate prevalence and to identify factors associated with rheumatic diseases in older adults of the urban area of a municipality in Southern Brazil. Methods: Cross-sectional population-based study, conducted in 2008 in the city of Bagé-RS, Brazil with older adults aged 60 years or over. The outcome was defined from the question "Has any doctor told you that you have rheumatism, arthritis or arthrosis?" Poisson regression was used for the crude and adjusted analysis. Results: A total of 1,593 participants were interviewed. $27.3 \%$ (95\% CI 25.0-29.5) reported having medical diagnosis of at least one of the rheumatic diseases studied. In the adjusted analysis, it was found that female sex $(\mathrm{RP}=2.86$; 95\% CI 2.28-3.59; $\mathrm{p} \leq 0.001)$, without schooling $(\mathrm{RP}=1.24$; 95\% CI 1.0-1.58; $\mathrm{p}=0.047)$, not living alone ( $\mathrm{RP}=1.29 ; 95 \% \mathrm{CI} 1.03-1.61 ; \mathrm{p}=0.024)$, poor self-perception of health $(\mathrm{PR}=1.54 ; 95 \% \mathrm{CI} 1.63-2.02 ; \mathrm{p}=0.001)$, spinal problems $(\mathrm{PR}=1,96 ; 95 \% \mathrm{CI} 1.67-2.31 ; \mathrm{p} \leq 0.001)$, fall in the last year $(\mathrm{PR}=1.22 ; 95 \%$ CI $1.04-$ $1.43 ; \mathrm{p}=0.013)$, incapacity for instrumental activities of daily living $(\mathrm{PR}=1.20 ; 95 \%$ CI 1.02-1.41; $\mathrm{p}=0.028)$ and healthcare appointment in the last 3 months $(\mathrm{PR}=1.20$; 95\% CI 1.01-1.42; $\mathrm{p}=0.035$ ) were associated with the presence of rheumatic diseases (rheumatism, arthritis and arthrosis). Conclusion: It is suggested that care of musculoskeletal problems of the spine should be increased, in order to reduce falls and functional disability in older adults, based on actions focused on the prevention of these problems.
\end{abstract}

Keywords: aged; rheumatic diseases; musculoskeletal development; prevalence; epidemiology.

\section{INTRODUCTION}

Musculoskeletal and joint diseases are the main causes of pain in older adults, accounting for about $40.0 \%$ of chronic diseases and $20.0 \%$ of health expenditures ${ }^{1,2}$. Rheumatic diseases, such as arthritis, arthrosis and/or rheumatism, constitute a group of more than 100 pathologies with similar involvement of synovial joints and symptoms of pain, edema, stiffness, and mobility limitation ${ }^{3,4}$. 
Worldwide, it is estimated that $18.0 \%$ of women and $9.6 \%$ of men over 60 years of age have rheumatic disorder of some kind ${ }^{5}$. In Brazil, data from the national household sample survey have pointed to rheumatic diseases as a more prevalent disease condition among older adults, since the disease affects $24.2 \%$ of the national population ${ }^{6,7}$. Despite high prevalence of recurrent diseases in the elderly population, there are still few population-based studies in Brazil that address the outcome, considering that most of the research with older adults presents the diseases as an exposure factor.

Some factors have been associated with the presence of rheumatic diseases, such as female sex, increasing age, low schooling, lower income, obesity, sedentary lifestyle, smoking and functional disability ${ }^{4,8,9}$.

In addition, rheumatic diseases considerably reduce the quality of life of the older adults due to their progressive, chronic course and performance impact on doing basic activities of daily living, leading to functional disability, social isolation and depression ${ }^{10}$. Inevitably, rheumatic diseases and their consequences carry a high cost for health systems, being among the most prevalent causes of hospital admissions in the world. In the group of musculoskeletal diseases, they account for the 3rd highest cost of hospitalization in Brazil ${ }^{11}$.

This study aimed to calculate prevalence and to identify factors associated with rheumatic diseases in older adults in the urban area of a municipality in the South of Brazil.

\section{METHODS}

This is a cross-sectional population-based study, conducted between July and November 2008, with a sample of individuals aged 60 years or older residing in the urban area and located in the area covered by primary health care services provided by the Brazilian public health system of the municipality of Bagé, Rio Grande do Sul, Brazil.

Data collection was performed respecting the area covered by the Brazilian public health system primary healthcare centers. The study included all 20 municipal Primary Healthcare Centers, being 15 Family Health Strategy Centers and five Traditional Primary Care Centers. The Family Health Strategy coverage accounted for $51 \%$ of the urban population. In order to locate the sample, the covered area of each Primary Healthcare Center was divided into micro-areas, with numerical identification of each block, randomizing the starting point of data collection. Aiming to ensure that all households had the same probability of comprising the sample, we systematically skipped one in every five residences.

All residents aged 60 years or older living in the selected households were invited to participate in the study. Interviews not performed after three attempts on different days and times were considered losses and/or refusals. Subjects who, at the time of the interview, were traveling, deprived of their liberty by judicial decision or living in long-term institutions were excluded from the study. In case of inability to answer the questionnaire, self-perception questions were not applied, and general questions were applied to the caregiver.

Data collection was performed face-to-face by previously trained interviewers who administered a structured questionnaire with pre-coded questions. To calculate the sample size, $10 \%$ of losses and refusals were considered, as was a design effect of 1.3. The study had $80 \%$ power to detect relative risks of 1.5 and exposures that affected at least $4 \%$ of the population ${ }^{12}$.

The dependent variable "rheumatic diseases" was self-reported and defined through the affirmative answer to the question "Has any doctor told you that you have rheumatism, arthritis or arthrosis?". The independent variables included: sex (male/female), age (60 to 70,71 to 80,85 or more), self-reported skin color (white, black, brown/indigenous/yellow), marital status (married or with partner, widowed, single or separated), schooling (none, 1 to 7,8 or more years), economic classification according to ANEP (Associação Brasileira de Empresas de Pesquisa) (A/B, C, $\mathrm{D} / \mathrm{E}$ ), living alone (no/yes), smoking (ex-smoker, smoker, never smoked), alcohol consumption in the last 30 days (no/yes), selfperception of health (great/good, regular, poor), feeling about life (dissatisfied/satisfied), compared with other people your age as your health is (better/worse), fall in the last year (no/yes), bone fracture in the last year (no/yes), depression (no/yes - collected through the Geriatric Depression Scale, GDS-15 - present account: score 0 to $5 /$ absent: score $\geq 6)^{13}$, self-reported medical diagnosis of systemic arterial hypertension (SAH) (no/yes), diabetes mellitus (DM) (no/yes) and spinal problem (no/yes); disability (no/yes - need for partial or total help for at least one of the activities investigated): basic disability in daily life (BADL); instrumental disabilities for daily living (IADL) (Katz Index and Lawton and Brody Scale, both validated in Brazil $)^{14,15}$ medical consultation no emergency in the last three months (no/yes) and medical home care (no/yes).

For data analysis, a descriptive analysis was initially performed by calculating prevalence and respective confidence intervals (95\%) of each of the variables of interest. Gross and adjusted analysis was performed to evaluate associated factors. The adjusted analysis was performed with the objective of evaluating the association of the outcome with the independent variables, using a hierarchical model on five levels, controlling possible confounding factors and the exposure variables. The first level was comprised of demographic and socioeconomic variables; the second level contained behavioral variables; the third level contained variables of health perception and health situation; the fourth level contained variables of basic activities (BADL) and instrumental activities (IADL) of daily life and the fifth 
level contained variables about health service use. In the adjusted analysis, all the variables of the hierarchical model were initially included. Backward adjustment was used for hierarchical levels, with only those with $\mathrm{p} \leq 0.20$ remaining in the model, through Poisson regression with robust variance adjustment. The prevalence ratios (PR) and respective confidence intervals (95\% CI) were calculated and the Wald heterogeneity and linear trend test values were measured. Associations with $\mathrm{p}$-value $\leq 0.05$ were considered statistically significant.

The analysis was conducted using Stata version ${ }^{\circledR} 14.0$ (StataCorp./CollegeStation, United States).

This research was approved by the Research Ethics Committee of Faculdade de Medicina da Universidade Federal de Pelotas Report No. 15/08. Ethical principles were ensured, and absolute anonymity was guaranteed and the participants signed a Free and Informed Consent form

\section{RESULTS}

Our analysis included the 1,593 participants interviewed, with 7\% losses and refusals. Most of the sample consisted of women $(62.7 \%)$, individuals aged $60-70$ years $(53.2 \%)$ and white race/skin color (78.6\%). Regarding marital status, $51.2 \%$ of the older adults were married or living with a partner; $17.6 \%$ reported living alone. The majority (54.5\%) reported having 1 to 7 years of schooling and $27.1 \%$ belonged to the D/E economic class (Table 1).

Regarding the behavioral variables, $15.3 \%$ were smokers and $16.0 \%$ had consumed alcohol in the last 30 days. In relation to self-assessment, $34.1 \%$ of the older adults perceived their health as regular; $94.3 \%$ said they were satisfied with their lives and $10.7 \%$ considered their health worse than other people in general. Regarding morbidities, more than half of the interviewees (55.3\%) had a medical diagnosis of systemic arterial hypertension, $15.1 \%$ had diabetes mellitus, $17.2 \%$ had depression, $37.4 \%$ had a spinal problem, $28.0 \%$ reported having suffered a fall in the last year and $54.6 \%$ of the respondents said they had a medical appointment the last three months (Table 1).

Occurrence of rheumatic diseases (rheumatism, arthritis, and arthrosis) was reported by $27.3 \%$ (95\% CI 25.0-29.5) of the older adults. Table 2 shows the gross and adjusted analyses of the outcome according to the independent variables. In the adjusted analysis, females presented a 2.86-fold higher probability of occurrence of the outcome compared to males $(\mathrm{PR}=2.86,95 \% \mathrm{CI}$ 2.28-3.59; $\mathrm{p} \leq 0.001)$. Patients without no schooling were more likely to report rheumatic diseases ( $P R=1.24,95 \%$ CI 1.0-1.58; $\mathrm{p}=0.047$ ) when compared to those with 8 years or more of study. The participants who said they did not live alone had $29.0 \%$ more prevalence of the outcome ( $\mathrm{PR}=1.29,95 \%$ CI 1.03-1.61; $\mathrm{p}=0.024)$ than those who lived alone (Table 2).
Table 1: Description the sample according to independent variables. Bagé-RS, Brazil. 2008 ( $\mathrm{N}=1,593)$

\begin{tabular}{|c|c|c|c|}
\hline \multicolumn{2}{|l|}{ Variables } & $\mathbf{N}$ & $\%$ \\
\hline \multirow{2}{*}{ Sex } & Male & 593 & 37.2 \\
\hline & Female & 1000 & 62.8 \\
\hline \multirow{3}{*}{ Age } & $60-70$ & 848 & 53.3 \\
\hline & $71-80$ & 512 & 32.1 \\
\hline & 85 or more & 233 & 14.6 \\
\hline \multirow{3}{*}{ Skin color (self reported) } & White & 1252 & 78.6 \\
\hline & Black & 139 & 8.7 \\
\hline & Brown/Indigenous/Yellow & 202 & 12.7 \\
\hline \multirow{3}{*}{ Marital status $(n=1,592)$} & Married or with partner & 816 & 51.3 \\
\hline & Widower & 238 & 14.9 \\
\hline & Not married ou separate & 538 & 33.8 \\
\hline \multirow{3}{*}{ Schooling $(n=1,572)^{\star \star \star}$} & None & 372 & 23.7 \\
\hline & $1-7$ years & 858 & 54.6 \\
\hline & 8 years or more & 342 & 21.7 \\
\hline \multirow{3}{*}{$\begin{array}{l}\text { Economic classification } \\
(\text { ANEP) })^{\#}(n=1,581)^{\star * *}\end{array}$} & $\mathrm{~A} / \mathrm{B}$ & 537 & 34.0 \\
\hline & C & 615 & 38.9 \\
\hline & $D / E$ & 429 & 27.1 \\
\hline \multirow{2}{*}{ Living alone } & No & 1313 & 82.4 \\
\hline & Yes & 280 & 17.6 \\
\hline \multirow{3}{*}{ Smoke $(n=1,592)^{\star \star \star}$} & Ex-smoker & 717 & 45.1 \\
\hline & Smoker & 244 & 15.3 \\
\hline & Never smoked & 631 & 39.6 \\
\hline \multirow{2}{*}{$\begin{array}{l}\text { Alcohol consumption (last } \\
30 \text { days) }(n=1,584)^{\star \star \star}\end{array}$} & No & 1330 & 84.0 \\
\hline & Yes & 254 & 16.0 \\
\hline \multirow{3}{*}{$\begin{array}{l}\text { Self-perception of health } \\
(n=1,540)^{\star \star \star}\end{array}$} & Great/good & 906 & 58.8 \\
\hline & Regular & 525 & 34.1 \\
\hline & Poor & 109 & 7.1 \\
\hline \multirow{2}{*}{$\begin{array}{l}\text { Feeling about life } \\
(n=1,536)\end{array}$} & Satisfied & 1449 & 94.3 \\
\hline & Unsatisfied & 87 & 5.7 \\
\hline \multirow{3}{*}{$\begin{array}{l}\text { Health compared to other } \\
\text { people }(n=1,532)\end{array}$} & Better & 684 & 44.6 \\
\hline & Equal & 684 & 44.6 \\
\hline & Worse & 164 & 10.6 \\
\hline \multirow{2}{*}{$\begin{array}{l}\text { Fall (last year) } \\
(n=1,591)^{\star \star \star}\end{array}$} & No & 1145 & 72.0 \\
\hline & Yes & 446 & 28.0 \\
\hline \multirow{2}{*}{$\begin{array}{l}\text { Bone fracture (last year) } \\
(n=1,592)^{\star \star \star}\end{array}$} & No & 1528 & 96.0 \\
\hline & Yes & 64 & 4.0 \\
\hline \multirow{2}{*}{$\begin{array}{l}\text { Spinal problem (self- } \\
\text { reported) }(n=1,591)^{\star \star \star}\end{array}$} & No & 996 & 62.6 \\
\hline & Yes & 595 & 37.4 \\
\hline \multirow{2}{*}{$\begin{array}{l}\text { Depression (GDS15) })^{\# \#} \\
(n=1,512)^{\star \star \star}\end{array}$} & No & 1240 & 82.0 \\
\hline & Yes & 272 & 18.0 \\
\hline \multirow{2}{*}{$\begin{array}{l}\text { Systemic Arterial } \\
\text { Hypertension (self- } \\
\text { reported) }\end{array}$} & No & 712 & 44.7 \\
\hline & Yes & 881 & 55.3 \\
\hline \multirow{2}{*}{$\begin{array}{l}\text { Diabetes Mellitus (self- } \\
\text { reported) }\end{array}$} & No & 1352 & 84.8 \\
\hline & Yes & 241 & 15.1 \\
\hline \multirow{2}{*}{$\begin{array}{l}\text { Basic activities of daily } \\
\text { living (BADL) }\end{array}$} & Without disability & 1424 & 89.4 \\
\hline & With disability & 169 & 10.6 \\
\hline \multirow{2}{*}{$\begin{array}{l}\text { Instrumental activities } \\
\text { of daily living (IADL) } \\
(n=1,589)^{\star \star \star}\end{array}$} & Without disability & 1045 & 65.8 \\
\hline & With disability & 544 & 34.2 \\
\hline Medical consultation & No & 723 & 45.4 \\
\hline $\begin{array}{l}\text { no emergency (last } 3 \\
\text { months) }(n=1,591)^{\star \star \star}\end{array}$ & Yes & 868 & 54.6 \\
\hline Medical home care & No & 1548 & 97.2 \\
\hline & Yes & 45 & 2.8 \\
\hline
\end{tabular}

\#ANEP: According to the Brazil Economic Classification Criterion: Associação Brasileira de Empresas de Pesquisa

\#"GDS15: Geriatric Depression Scale, GDS-15; " 'Sample total for each variable after losses. 
Table 2: Crude and adjusted association between independent variables and the outcome in older adults in the city of Bagé/RS, Brazil. 2008.

\begin{tabular}{|c|c|c|c|c|c|c|}
\hline \multirow{2}{*}{ Variables } & \multicolumn{3}{|c|}{ Crude analysis } & \multicolumn{3}{|c|}{ Adjusted analysis } \\
\hline & PR & CI 95\% & $p^{*}$ & $\begin{array}{l}\text { PR } \\
\end{array}$ & Cl 95\% & $p^{*}$ \\
\hline \multicolumn{7}{|l|}{$1^{\circ}$ Level $^{\mathrm{a}}$} \\
\hline \multicolumn{7}{|l|}{ Sex } \\
\hline Male & 1 & & \multirow{2}{*}{$<0.001$} & 1 & & \multirow{2}{*}{$<0.001$} \\
\hline Female & 2.83 & $2.26-3.56$ & & 2.86 & $2.28-3.59$ & \\
\hline \multicolumn{7}{|l|}{ Age } \\
\hline $60-70$ & 1 & $0.83-1.20$ & \multirow{3}{*}{0.124} & 1 & & \multirow{3}{*}{0.649} \\
\hline $71-80$ & 1.02 & $1.00-1.54$ & & 0.98 & $0.82-1.18$ & \\
\hline 85 or more & 1.24 & $0.89-1.37$ & & 1.09 & $0.88-1.37$ & \\
\hline \multicolumn{7}{|l|}{ Skin color (self referenced) } \\
\hline White & 1 & & \multirow{3}{*}{0.589} & 1 & & \multirow{3}{*}{0.523} \\
\hline Black & 1.02 & $0.77-1.36$ & & 0.96 & $0.73-1.28$ & \\
\hline Brown/Indigenous/Yellow & 1.28 & $0.90-1.42$ & & 1.13 & $0.90-1.41$ & \\
\hline \multicolumn{7}{|l|}{ Marital status } \\
\hline Married or with partner & 1 & & \multirow{3}{*}{0.002} & 1 & & \multirow{3}{*}{0.890} \\
\hline Widower & 1.13 & $0.89-1.44$ & & 0.97 & $0.75-1.25$ & \\
\hline Not married ou separate & 1.36 & $1.15-1.62$ & & 1.03 & $0.84-1.25$ & \\
\hline \multicolumn{7}{|l|}{ Schooling } \\
\hline 8 years or more & 1 & & \multirow{3}{*}{$0.029^{\star \star}$} & 1 & & \\
\hline $1-7$ years & 1.10 & $0.82-1.25$ & & 1.01 & $0.82-1.24$ & $0.047^{\star \star}$ \\
\hline None & 1.29 & $1.02-1.62$ & & 1.24 & $1.01-1.58$ & \\
\hline Economic classification (ANE & & & & & & \\
\hline$A / B$ & 1 & & & 1 & & \\
\hline C & 0.95 & $0.79-1.15$ & 0.837 & 0.99 & $0.81-1.20$ & 0.425 \\
\hline $\mathrm{D} / \mathrm{E}$ & 1.00 & $0.81-1.22$ & & 1.13 & $0.89-1.45$ & \\
\hline Living alone & & & & & & \\
\hline Yes & 1 & & 0102 & 1 & & 0021 \\
\hline No & 1.21 & $0.96-1.52$ & 0.102 & 1.29 & $1.03-1.61$ & 0.024 \\
\hline $2^{\circ}$ Level $^{b}$ & & & & & & \\
\hline Smoke & & & & & & \\
\hline Never smoke & 1 & & & 1 & & \\
\hline Ex-amoker & 1.05 & $0.80-1.38$ & $<0.001$ & 0.96 & $0.74-1.24$ & 0.708 \\
\hline Smoker & 1.49 & $1.24-1.78$ & & 1.05 & $0.88-1.26$ & \\
\hline Alcohol consumption (last 30 & & & & & & \\
\hline No & 1 & & & 1 & & \\
\hline Yes & 1.68 & $1.27-2.23$ & $<0.001$ & 1.20 & $0.90-1.59$ & 0.209 \\
\hline $3^{\circ}$ Level $^{\mathrm{c}}$ & & & & & & \\
\hline Self-perception of health & & & & & & \\
\hline Great/good & 1 & & & 1 & & \\
\hline Regular & 1.72 & $1.45-2.04$ & $<0.001^{\star *}$ & 1.43 & $1.20-1.69$ & $<0.001^{* *}$ \\
\hline Poor & 2.12 & $1.66-2.72$ & & 1.54 & 1.63-2.02 & \\
\hline Feeling about life & & & & & & \\
\hline Unsatisfied & 1 & & 00001 & 1 & & 0360 \\
\hline Satisfied & 0.61 & $0.47-0.78$ & $<0.001$ & 0.88 & $0.67-1.16$ & 0.369 \\
\hline Compared with other people & & & & & & \\
\hline Best & 1 & & & 1 & & \\
\hline Equal & 1.05 & $0.88-1.25$ & 0.217 & 1.02 & $0.87-1.20$ & 0.809 \\
\hline Worse & 1.25 & $0.97-1.61$ & & 0.94 & $0.70-1.24$ & \\
\hline Fall (last year) & & & & & & \\
\hline No & 1 & & 000 & 1 & & 0010 \\
\hline Yes & 1.59 & $1.35-1.86$ & $<0.001$ & 1.22 & $1.04-1.43$ & 0.013 \\
\hline Bone fracture (last year) & & & & & & \\
\hline No & 1 & & & 1 & & $5-11$ \\
\hline Yes & 1.21 & $0.85-1.74$ & 0.293 & 0.89 & $0.64-1.25$ & 0.511 \\
\hline
\end{tabular}


Table 2: Continuation.

\begin{tabular}{|c|c|c|c|c|c|c|}
\hline \multirow{2}{*}{ Variables } & \multicolumn{3}{|c|}{ Crude analysis } & \multicolumn{3}{|c|}{ Adjusted analysis } \\
\hline & PR & $\mathrm{Cl} 95 \%$ & $p^{*}$ & PR & Cl 95\% & $p^{*}$ \\
\hline \multicolumn{7}{|c|}{ Spinal problem (self-reported) } \\
\hline No & 1 & & \multirow{2}{*}{$<0.001$} & 1 & & \multirow{2}{*}{$<0.001$} \\
\hline Yes & 2.41 & $2.05-2.83$ & & 1.96 & $1.67-2.31$ & \\
\hline \multicolumn{7}{|c|}{ Depression (GDS15) \#\# } \\
\hline No & 1 & & \multirow{2}{*}{$<0.001$} & 1 & & \multirow{2}{*}{0.957} \\
\hline Yes & 1.43 & 1.19- 1.72 & & 0.99 & $0.81-1.23$ & \\
\hline \multicolumn{7}{|c|}{ Systemic Arterial Hypertension (self-reported) a } \\
\hline No & 1 & & \multirow{2}{*}{$<0.001$} & 1 & & \multirow{2}{*}{0.726} \\
\hline Yes & 1.35 & $1.14-1.59$ & & 0.97 & $0.82-1.14$ & \\
\hline \multicolumn{7}{|c|}{ Diabetes Mellitus (self-reported)a } \\
\hline No & 1 & & \multirow{2}{*}{0.098} & 1 & & \multirow{2}{*}{0.261} \\
\hline Yes & 1.19 & $0.97-1.46$ & & 1.12 & $0.92-1.37$ & \\
\hline \multicolumn{7}{|l|}{$4^{\circ}$ Level $^{d}$} \\
\hline \multicolumn{7}{|c|}{ Basic activities of daily living (BALD) } \\
\hline No & 1 & & \multirow{2}{*}{0.360} & 1 & & \multirow{2}{*}{0.982} \\
\hline Yes & 1.12 & $0.88-1.43$ & & 1.01 & $0.77-1.32$ & \\
\hline \multicolumn{7}{|c|}{ Instrumental activities of daily living (IADL) } \\
\hline No & 1 & & \multirow{2}{*}{$<0.001$} & 1 & & \multirow{2}{*}{0.028} \\
\hline Yes & 1.32 & $1.13-1.55$ & & 1.20 & $1.02-1.41$ & \\
\hline \multicolumn{7}{|l|}{$5^{\circ}$ level $^{\mathrm{e}}$} \\
\hline \multicolumn{7}{|c|}{ Medical consultation no emergency (last 3 months) } \\
\hline No & 1 & & \multirow{2}{*}{0.012} & 1 & & \multirow{2}{*}{0.035} \\
\hline Yes & 1.30 & $1.06-1.61$ & & 1.20 & $1.01-1.42$ & \\
\hline \multicolumn{7}{|c|}{ Medical home care } \\
\hline No & 1 & & \multirow{2}{*}{$<0.001$} & 1 & & \multirow{2}{*}{0.102} \\
\hline Yes & 2.01 & $1.51-2.68$ & & 1.34 & $0.94-1.89$ & \\
\hline
\end{tabular}

Rheumatic diseases presented a linear tendency in the association with self-perception of health, and their prevalence was higher in individuals with regular perception ( $\mathrm{PR}=1.43$, 95\% CI 1.20$1.69)$ and poor perception ( $\mathrm{PR}=1.54,95 \% \mathrm{CI} 1.63-2.02)$ compared to the older adults with good or optimal health self-evaluation $(\mathrm{p}=0.001)$ (Table 2).

Prevalence of rheumatic diseases was almost twice as high in older adults who reported problems in the spine $(\mathrm{PR}=1.96$, 95\% CI 1.67-2.31; $\mathrm{p} \leq 0.001)$. The participants who reported having suffered at least one fall in the last year presented a $22.0 \%$ higher probability of the occurrence of the outcome investigated $(\mathrm{PR}=1.22$, 95\% CI 1.04-1.43; $\mathrm{p}=0.013$ ) (Table 2).

The presence of functional disability for activities for instrumental of daily living showed a statistically significant association with the presence of rheumatic diseases ( $P R=1.20,95 \%$ CI 1.02$1.41 ; \mathrm{p}=0.028)$. Similarly, the older adults who had medical consultation no emergency in the three months prior to the survey had a $20.0 \%$ higher probability of the outcome when compared to those who had not had an appointment in this period $(\mathrm{PR}=1.20$, 95\% CI 1.01-1.42; $\mathrm{p}=0.035$ ) (Table 2).

\section{DISCUSSION}

This study evaluated the prevalence of rheumatic diseases (rheumatism, arthritis, and arthrosis) and their associated factors in older adults in the urban area of a municipality in the extreme south of Brazil. The results identified a high prevalence of rheumatic diseases (27.3\%), being associated with female sex, without schooling, not living alone, poor self-perception of health, fall in the last year, self-reported diagnosis of spinal problems, presence of incapacity for IADL and medical consultation no emergency in the last three months.

This result resembles that of other international and national surveys $^{7,16-19}$. The PNAD, which used similar methodology and 
data collected in the same year as this study, found presence of rheumatic diseases in $24.2 \%$ of the older adults investigated ${ }^{6,7}$. Similar to what was observed in other studies, older women are more likely to have the outcome when compared to older men. The literature suggests that the increased presence of musculoskeletal diseases, including rheumatic diseases, among women may be linked to biological factors such as hormonal alterations occurring in puberty, menstruation and menopause, but there are still gaps in the differences between the sexes in the onset of rheumatic disease $\mathrm{s}^{20,21}$.

We observed an inverse association between years of schooling and occurrence of rheumatic diseases among the elderly. The possibility of greater involvement of older adults with lower educational level in occupational activities of high physical demands and musculoskeletal load over time would increase the chance of this population developing rheumatic diseases ${ }^{17}$.

The significantly greater occurrence of the outcome among those who did not live alone suggests its relationship with the physical impairment that the diseases bring. Older people with rheumatic problems have less independence and autonomy to perform daily activities, these being conditions necessary for living alone ${ }^{22}$.

It was also observed that the worse the perception of health, the higher the prevalence of the outcome studied. Considering that self-perceived health is a proven indicator of the health status of individuals such as physical, cognitive, emotional and mortality conditions, we understand that this result indicates that rheumatic diseases directly affect physical and emotional health, and this can cause a decline in functional status and quality of life in the elderly ${ }^{1,23}$.

With regard to falls, it was found that the presence of rheumatic diseases was associated with a fall in the last year. Similarly, a national study ${ }^{24}$ and an international study ${ }^{25}$ showed a higher proportion of arthritis/arthrosis in older adults who suffered falls in the last year. Although the cited studies present methodological differences and consideration of reverse causality bias is needed, it is believed that this result is due to the impairment that rheumatic diseases cause to the joints, causing rigidity and limitation in mobility, causing difficulty in walking and increasing susceptibility to falls ${ }^{4,26}$.

The results showed a $96.0 \%$ higher probability of spinal problems among the elderly with rheumatic diseases. It is believed that the justification for this result is similar to the higher proportion of falls in this population. The vertebral column is the longitudinal axis of the body responsible for guaranteeing the upright position against the action of gravity and enables walking. In the case of patients with rheumatic diseases, their functions are altered due to the involvement of the joints and adjacent structures, which will inevitably cause chronic pain, progressive movement limitation and disability ${ }^{1,27}$.
As for the association between rheumatic diseases and functional disability for instrumental activities, this result corroborates the findings of Alves ${ }^{28}$ when assessing functional disability in older adults. In this sense, the literature suggests greater care for the functional limitations in this population, considering that incapacity triggers personal and family suffering, greater demands for health care, social and economic resources ${ }^{7}$.

According to previous findings ${ }^{29}$ the results of this research indicate that the older adults who consulted their doctor in the last three months are more likely to report rheumatic diseases. However, considering that the use of health services is an important marker of the poorer health conditions of the individual, we must once again consider the possibility of reverse causality, inherent to the design of this study ${ }^{29}$.

In assessing the burden of musculoskeletal diseases on health systems, noting that 31.6 million are used drugs each year to treat musculoskeletal and joint diseases, including rheumatic diseases in England and Wales, and that in this same period 1.7 million outpatient visits were made to rheumatology specialty services in England. Likewise, a follow-up study carried out in Brazil showed that annual expenditure on the treatment of rheumatoid arthritis, one of the most prevalent rheumatic diseases, is approximately $30,000 \mathrm{BRL}$ per patient, and that approximately $70 \%$ of this amount is funded by the Health Care System - SUS ${ }^{30}$.

It should be noted that rheumatic diseases are also an important risk factor for mortality, both in the adult population and among older adults. In Scotland and Northern Ireland in 2015, $34.0 \%$ and $31.0 \%$ of musculoskeletal deaths were attributed to rheumatoid arthritis or osteoarthritis, respectively. While in England and Wales, 19\% of deaths were attributed to rheumatoid arthritis that year ${ }^{29}$.

Considering the data presented in this study, it is relevant to mention in this discussion the need to evaluate access and quality of the care offered to these patients, although these data have not been evaluated in this study, important points of discussion for proposing new studies and strategies for care for this population ${ }^{31}$ are reports that, worldwide, access to and management of care for patients with rheumatic and musculoskeletal diseases remain deficient. In facing this panorama, we must invest in professional qualification, guaranteeing more accurate and early diagnosis and referrals. Therefore, it is suggested that new studies be conducted with a focus on the evaluation of the quality of care delivered to this population in primary care services.

Some limitations also need to be considered, namely use of self-reported medical diagnosis of arthritis/arthrosis/rheumatism without radiographic confirmation, and the possibility of memory bias due to the study design and population studied.

In conclusion, the results of this study made it possible to know the proportion of older adults with rheumatic diseases and their associated factors, namely: female gender, without education, does 
not live alone, poor self-perception of health, spinal problems, falling in the last year, presence of incapacity for instrumental activities of daily living and health consultation in the last 3 months.

The factors found, such as spinal problems, falls and functional incapacity are amenable to prevention, management and treatment through simple interventions, constant monitoring and quality care, which could reduce the occurrence of this outcome. It should be pointed that the results of this study can also help health professionals, supporting the choice based on evidence of treatments for the population with rheumatic diseases.

\section{REFERENCES}

1. Falsarella GR, Coimbra IB, Neri AL, Barcelos CC, Costallat LTL, Carvalho OMF, et al. Impact of rheumatic diseases and chronic joint symptoms on quality of life in the elderly. Arch Gerontol Geriatr. 2012;54(2):e77-82. https://doi.org/10.1016/j.archger.2011.06.038

2. Torres SF, Neri AL, Borim FSA. Overview of Rheumatic Diseases in the Elderly: The FIBRA Study. Pan Am J Aging Res. 2016;4(1):21-30. https://doi.org/10.15448/2357-9641.2016.1.23765

3. Gebauer S, Schootman M, Xian H, Xaverius P. Neighborhood built and social environment and meeting physical activity recommendations among mid to older adults with joint pain. Prev Med Rep. 2020;18:101063.

https://doi.org/10.1016/j.pmedr.2020.101063

4. Granados Y, Cedeño L, Rosillo C, Berbin S, Azocar M, Molina $\mathrm{ME}$, et al. Prevalence of musculoskeletal disorders and rheumatic diseases in an urban community in Monagas State, Venezuela: a COPCORD study. Clin Rheumatol. 2015;34(5):871-7. http://dx.doi.org/10.1007/s10067-014-2689-9

5. Woolf AD, Pfleger B. Burden of major musculoskeletal conditions. Bull World Health Organ. 2003;81(9):646-56

6. Barros MB de A, Francisco PMSB, Zanchetta LM, César CLG. Trends in social and demographic inequalities in the prevalence of chronic diseases in Brazil. PNAD : 2003-2008. Cienc Saude Coletiva. 2011;16(9):3755-68.

http://dx.doi.org/10.1590/S1413-81232011001000012

7. Lima-Costa MF, Matos DL, Camargos VP, Macinko J. Tendências em dez anos das condições de saúde de idosos brasileiros: evidências da Pesquisa Nacional por Amostra de Domicílios (1998, 2003, 2008). Cienc Saude Coletiva. 2011;16(9):3689-96 http://dx.doi.org/10.1590/S1413-81232011001000006

8. Smolen JS, Aletaha D, Mcinnes IB. Rheumatoid arthritis. Lancet. 2016;388(10055):2023-38 http://doi.org/10.1016/S0140-6736(16)30173-8

9. Brenton-Rule A, Dalbeth N, Bassett S, Menz HB, Rome K. The incidence and risk factors for falls in adults with rheumatoid arthritis: a systematic review. Semin Arthritis Rheum. 2015;44(4):389-98. http://doi.org/10.1016/j.semarthrit.2014.08.001

10. Wysocka-skurska I, Sierakowska M, Kułak W. Evaluation of quality of life in chronic, progressing rheumatic diseases based on the example of osteoarthritis and rheumatoid arthritis. Clin Interv Aging. 2016;11:1741-50.

http://doi.org/10.2147/CIA.S116185

11. Silveira RE, Santos AS, Sousa MC, Monteiro TSA. Gastos relacionados a hospitalizações de idosos no Brasil: perspectivas de uma década. Einstein. 2013;11(4):514-20. https://doi.org/10.1590/S1679-45082013000400019

12. Thumé E, Facchini LA, Wyshak G, Campbell P. The utilization of home care by the elderly in Brazil's primary health care system. Am J Public Health. 2011;101(5):868-74. https://doi.org/10.2105/AJPH.2009.184648
13. Almeida OP, Almeida SA. Confiabilidade da versão brasileira da Escala de Depressão em Geriatria (GDS) versão reduzida. Ara Neuropsiquiatr. 1999;57(2-B):421-26. https://doi.org/10.1590/S0004-282X1999000300013

14. Lawton MP, Brody EM. Assessment of older people: self-maintaining and instrumental activities of daily living. Gerontologist. 1969;9(3 part 1):179-86.

https://doi.org/10.1093/geront/9.3_Part_1.179

15. Katz S, Ford AB, Moskowitz RW, Jackson BA, Jaffe MW. Studies of Illness in the Aged. The Index of ADL: a Standardized Measure of Biological and Psychosocial Function. JAMA. 1963;185:914-9. https://doi.org/10.1001/jama.1963.03060120024016

16. Silva EF, Paniz VMV, Laste G, Torres ILS. Prevalência de morbidades e sintomas em idosos: um estudo comparativo entre zonas rural e urbana. Cienc Saude Coletiva. 2013;18(4):1029-40. https://doi.org/10.1590/S1413-81232013000400016

17. Liu Q, Wang S, Lin J, Zhang Y. The burden for knee osteoarthritis among Chinese elderly: estimates from a nationally representative study. Osteoarthr Cartil. 2018;26(12):1636-42. http://dx.doi.org/10.1016/j.joca.2018.07.019

18. Bezerra MAM, Hellwig N, Pinheiro GRC, Lopes CS. Prevalence of chronic musculoskeletal conditions and associated factors in Brazilian adults - National Health Survey. BMC Public Health. 2018;18(1):287. http://dx.doi.org/10.1186/s12889-018-5192-4

19. Falsarella GR, Coimbra IB, Barcelos CC, Costallat LTL, Carvalho OMF, Coimbra AMV. Prevalence and factores associated with rheumatic diseases and chronic joint symptons in the elderly. Geriatr Gerontol Int. 2013:13(4):1043-50. http://doi.org/10.1111/ggi.12052

20. Maynard C, Mikuls TR, Cannon GW, England BR, Conaghan PG, Østergaard M, et al. Sex Differences in the Achievement of Remission and Low Disease Activity in Rheumatoid Arthritis. Arthritis Care Res. 2020;72(3):326-33. http://doi.org/10.1002/acr.23873

21. Talsania M, Scofield $\mathrm{RH}$. Menopause and rheumatic disease. Rheum Dis Clin North Am. 2018;43(2):287-302. http://dx.doi.org/10.1016/j.rdc.2016.12.011

22. Nunes JD, Saes MO, Nunes BP, Thumé E, Siqueira FCV, Soares DC, et al. Indicadores de incapacidade funcional e fatores associados em idosos: estudo de base populacional em Bagé, Rio Grande do Sul. Epidemiol Serv Saude. 2017;26(2):295-304. http://dx.doi.org/10.5123/S1679-49742017000200007

23. Fausto S, Marco Di C, Marina C, Sonia F, Alessandro C, Marwin $G$. The impact of different rheumatic diseases on health-related quality of life: a comparison with a selected sample of healthy individuals using SF-36 questionnaire, EQ-5D and SF-6D utility values. Acta Biomed. 2018;89(4):541-57. http://dx.doi.org/10.23750/abm.v89i4.7298 
24. Nascimento JS, Tavares DMS. Prevalência e fatores associados a quedas em idosos. Texto Context Enferm. 2016;25(2):e0360015. http://dx.doi.org/10.1590/0104-07072016000360015

25. Wu H, Ouyang P. Fall prevalence, time trend and its related risk factors among elderly people in China. Arch Gerontol Geriatr. 2017;73:294-9

http://dx.doi.org/10.1016/j.archger.2017.08.009

26. Pimentel WRT, Pagotto V, Stopa SR, Hoffmann MCCL, Andrade FB, Souza Junior PRB, et al. Falls among Brazilian older adults living in urban areas: ELSI-Brazil. Rev Saude Publica. 2018;52(Supl 2):12s

http://dx.doi.org/10.11606/S1518-8787.2018052000635

27. Immonen $M$, Haapea $M$, Similä $H$, Enwald $H$, Keränen N, Kangas $\mathrm{M}$, et al. Association between chronic diseases and falls among a sample of older people in Finland. BMC Geriatrics. 2020;20:225. https://doi.org/10.1186/s12877-020-01621-9
28. Alves LC, Leite IC, Machado CJ. Factors associated with functional disability of elderly in Brazil : a multilevel analysis. Rev Saude Publica. 2010;44(3):468-78. https://doi.org/10.1590/S0034-89102010005000009

29. Ingram M, Symmons DPM. The burden of musculoskeletal conditions. Medicine. 2018;46(3):152-5.

https://doi.org/10.1016/j.mpmed.2017.12.005

30. Silva GD, Andrade EIG, Cherchiglia ML, Almeida AM, Guerra Júnior AA, Acurcio FA. Perfil de gastos com o tratamento da Artrite Reumatoide para pacientes do Sistema Único de Saúde em Minas Gerais, Brasil, de 2008 a 2013. Cienc Saude Coletiva. 2018;23(4):1241-53.

http://dx.doi.org/10.1590/1413-81232018234.16352016

31. Woolf AD, Gabriel S. Overcoming challenges in order to improve the management of rheumatic and musculoskeletal diseases across the globe. Clin Rheumatol. 2015:34(5):815-7. http://dx.doi.org/10.1007/s10067-015-2862-9 